\title{
Avaliação do tempo de cozimento da massa de queijo prato lanche sobre a umidade do produto
}

maturado

Francieli Dadalt', Rosiele Lappe Padilha', Voltaire Sant'Anna'

' Área da Vida e Meio Ambiente, Unidade em Encantado, Universidade Estadual do Rio Grande do Sul, Encantado, RS, Brasil E-mail: francidadalt@yahoo.com.br, rosielel@yahoo.com.br, voltaire-santanna@uergs.edu.br

Recebido em: 21 mar. 2019. Aceito: 24 maio 2019. DOI: http://dx.doi.org/I0.21674/2448-0479.xx.xxx-xxx

\section{Resumo}

Na fabricação de queijos, as características do produto final são determinadas pelas propriedades físico-químicas e microbiológicas do leite utilizado e pelas etapas envolvidas no processo de fabricação. As intervenções tecnológicas podem influenciar nos aspectos físico-químicos, definindo o padrão de qualidade do produto maturado. Este estudo teve como objetivo avaliar o efeito do processo de cozimento da massa de queijo sobre a umidade do produto maturado, uma vez que essas informações são escassas na literatura. As análises de umidade foram realizadas em tempo pré-determinado, assim, análises de correlação entre a temperatura final da massa de queijo, o tempo de cozimento, umidade inicial, umidade final, perda de umidade e taxa de secagem de Queijo Prato (Lanche) foram analisadas. Os resultados mostram que o tempo de cozimento está relacionado com a temperatura final da massa. Quanto maior o tempo de cozimento, menores serão os valores de umidade inicial, umidade final e haverá menores perdas de umidade do queijo maturado. Assim, o tempo de cozimento e a temperatura final da massa de queijo devem ser rigorosamente controlados, visando valores de umidade desejados no produto.

Palavras-chave: queijo; cozimento; temperatura; maturação; umidade.

\section{Abstract}

\section{Evaluation about how the cooking time of "time of prato lanche" cheese curd interferes in the moisture of the matured product}

When cheese is made, the characteristics of the final product are determined by the physic-chemical and microbiological properties of the used milk and by the steps involved in the manufacturing process. Technological interventions can influence the physic-chemical aspects, defining the quality standard of the mature product. The objective of this study was to evaluate the effect of the cooking process of the cheese curd upon the moisture from the matured product, since this information is scarce in the literature. As a result, correlation analyses between the final temperature of the cheese curd, cooking time, start moisture, final moisture, moisture loss and "Queijo Prato (Lanche)" cheese drying rate were analyzed. The results show that the cooking time is related to the final temperature of the curd. The higher the cooking time, the lower will be the initial moisture values and the final moisture. In addition to that, there will be less moisture losses of matured cheese. Therefore, the cooking time and the final temperature of the cheese curd must be critically controlled in order to achieve the desired moisture values in the product.

Keywords: cheese; cooking; temperature; maturation; moisture. 


\section{Introdução}

O Brasil classifica-se entre os países com maior produção de queijo no mundo e prospera a cada ano, impulsionada pelo aumento de vendas no varejo e pelo crescimento expressivo de serviços de alimentação, o que representa aumento do consumo de queijos industrializados (CHALITA et al., 2009). O queijo é um dos derivados do leite que possui destaque comercial também devido ao alto consumo, por ser fonte de nutrientes composto basicamente de proteínas, lipídios, carboidratos, sais minerais, cálcio, fósforo e vitaminas, entre elas A e B (PERRY, 2004).

Os diferentes tipos de queijos são caracterizados de acordo com o tipo de leite utilizado, forma de coagulação, fermento, período de maturação, consistência da massa, teor de gordura, teor de umidade entre outras características (PERRY, 2004). A classificação dos queijos dentre outros parâmetros é definida conforme o conteúdo de matéria gorda no extrato seco e porcentagem de umidade (BRASIL, 1996). O Queijo Prato (Lanche) encontra-se entre os queijos mais consumidos no Brasil, principalmente para o preparo de sanduíches (NARIMATSU et al., 2003). A principal característica que o diferencia é a obtenção de uma massa semi-cozida por coagulação enzimática, com remoção parcial do soro, lavada pela adição de água quente, prensada, salgada e maturada. O tempo mínimo de maturação exigido pela legislação atual é de 25 dias (BRASIL, 1997).

O processo de fabricação do Queijo Prato (Lanche) apresenta variações nos procedimentos de escolha, do tipo de cultura láctica utilizada, a temperatura de cozimento, o tipo de coagulante, o método de salga e o tempo de maturação (CHAVES, 20 I4). A etapa de cozimento promove a remoção parcial da lactose dos grãos da massa láctea, ocasionada pela contração dos grãos e o efeito osmótico, estes que complementam a retirada do soro iniciada pelo corte, aumenta a sinérese, além de alterar a textura, devido ao aumento de elasticidade da massa (KROLOW e RIBEIRO, 2006). O cozimento consiste em aumentar a temperatura da massa em $I^{\circ} \mathrm{C}$ a cada 2 minutos, até atingir a temperatura de aproximadamente $42^{\circ} \mathrm{C}$ (massa semicozida) (SILVA, 2005).

A maturação é o período de tempo que os queijos permanecem em câmaras reservadas, com condições de temperatura e umidade controladas, em que ocorrem diversas alterações físico-químicas, microbiológicas e sensoriais no alimento (ORDOÑEZ, 2005). Um dos objetivos da maturação de queijos é a perda de umidade, o que implica na classificação do produto. Conforme a legislação, o Queijo Prato (Lanche) é classificado como um queijo gordo (matéria gorda no extrato seco entre 45,0 e 59,9\%) e de média umidade (entre 36,0 e 45,9\%). A massa deve ser semicozida, lavada e então denominada para venda como Queijo Prato (Lanche ou Sandwich), Queijo Prato (Cobocó) ou Queijo Prato (Esférico ou Bola) (BRASIL, 1997).

Durante o processo de maturação ocorrem transformações físicas, bioquímicas e microbiológicas que alteram a composição química dos queijos. Os micro-organismos e enzimas alteram a estrutura das moléculas de proteínas e gorduras modificando a textura, sabor e aroma dos queijos. As três principais alterações que ocorre na maturação são: proteólise, glicólise, e lipólise (ORDOÑEZ, 2005). A maturação é caracterizada pela alteração das proteínas do queijo, ocasionada pela ação de várias enzimas, dentre elas as enzimas encontradas naturalmente no leite, no coalho e as proteases e peptidases do fermento lático. A proteólise é responsável por várias transformações, como mudanças na textura do queijo, devido à ruptura das cadeias de proteína, principalmente da $\square$ s I-caseína, como também a diminuição da atividade de água, devido à liberação de grupos carboxila e amina (DALLA ROSA et al., 2008).

A perda de umidade de um alimento está relacionada com diversos parâmetros de processo. No caso da maturação de queijos, além da temperatura e da umidade relativa na câmara de maturação, o processo para obtenção da massa láctea é outro parâmetro que pode influenciar de forma crítica na umidade final do produto (KROLOW e RIBEIRO, 2006). Estudos que tratam da influência do tempo de cozimento da massa de queijo na perda de umidade do produto são escassos na literatura. Assim, o objetivo deste trabalho foi avaliar o efeito do tempo de cozimento da massa do queijo na perda de umidade durante a maturação do Queijo Prato (Lanche).

\section{Material e Métodos}

\section{Fabricação do queijo}

O Queijo Prato (Lanche) foi produzido em uma indústria de laticínios situada no Vale do Taquari (Anta Gorda, RS). O leite destinado à fabricação dos produtos para análise físico-química foi padronizado a 3, I \% de 
gordura, pasteurizado a $72^{\circ} \mathrm{C}$ por 15 segundos, imediatamente resfriado à $32^{\circ} \mathrm{C}$ e transferido para o tanque de fabricação. Para cada tratamento foram utilizados 5.000L de leite, seguiu-se a adição da cultura starter (Chr. Hansen, Milwaukee, USA), composta por Lactococcus lactis subsp. lactis, Lactococcus lactis subsp. cremoris e Streptococcus salivarius subsp. thermophillus e solução de cloreto de cálcio 40\% (Launer, Estrela, RS). Após 30 minutos à $32^{\circ} \mathrm{C}$, foi adicionado o coagulante (Chy-max, Valinhos, SP).

O tempo de coagulação teve duração de aproximadamente 45 minutos, seguido do corte da massa com liras (primeiro no sentido horizontal, depois no vertical). Na sequência foi realizada a agitação, seguida de descanso para separação de parte do soro (cerca de $30 \%$ ). Após a primeira dessoragem, iniciou-se nova agitação, com a adição de água quente à $75,2 \pm 0,2^{\circ} \mathrm{C}$. $O$ tempo de cozimento da massa foi determinado através do tempo necessário para a massa atingir a temperatura entre $40^{\circ} \mathrm{C}$ e $42^{\circ} \mathrm{C}$ (conforme dados da tabela I). O tempo e temperatura utilizados foram diferentes em cada tratamento, com finalidade de pesquisar se a variação dos mesmos tem influência na umidade do produto pronto. Por conseguinte, foi retirada a massa láctea do tanque, seguindo da drenagem do soro no equipamento dreno prensa, onde permaneceu durante 15 minutos, realizou-se o corte da massa e enformagem, em formas retangulares providas de pequenos orifícios por onde sai parte do soro ainda retido, a prensagem foi realizada em prensas pneumáticas, seguida da retirada do queijo virando a parte superior para a inferior e prensou-se novamente, esta etapa de prensagem teve a mesma duração nos 10 tratamentos.

Depois de retirado das formas o queijo permaneceu imerso na solução salina $20 \%$ (massa/volume), durante 24 horas, seguida de secagem da massa em câmara fria à temperatura de $5,3 \pm 0,4^{\circ} \mathrm{C}$, por 24 horas. Após o término do tempo de secagem, as peças de queijo foram armazenadas em câmara de maturação por até 25 dias em temperatura de $5,5 \pm 0,5^{\circ} \mathrm{C}$ e umidade relativa de $81,9 \pm 0,3 \%$.

\section{Análise físico-química}

Cinco amostras de queijo para cada um dos 10 tratamentos avaliados foram retiradas em tempos de maturação pré-determinados ( $1,5,10,15,20$ e 25 dias) e analisados quanto à sua umidade, expressa em base úmida. As análises foram realizadas em duplicata seguindo a metodologia descrita pelo Ministério da Agricultura, Pecuária e Abastecimento (BRASIL, 2006).

\section{Análise estatística}

A taxa de secagem ( $\mathrm{dia}^{-1}$ ) foi calculada, a partir dos resultados de umidade do produto em função do tempo de maturação. Para isso, adequou-se os resultados de umidade e o tempo de maturação ao modelo matemático clássico de secagem (Equação I) através de regressão não linear com o software Statistica 7.0.

$$
\frac{U_{t}}{U_{0}}=\exp (-k t)
$$

Em que:

$\mathrm{U}_{\mathrm{t}}$ consiste na umidade no tempo de maturação no tempo $\mathrm{t}(\%)$

$\mathrm{U}_{0}$ consiste na umidade do produto antes da maturação (\%)

k: constante de secagem $\left(\right.$ dia $\left.^{-1}\right)$

t: tempo (dias)

As análises de correlação linear das variáveis entre a temperatura final da massa de queijo, o tempo de cozimento, umidade inicial, umidade final, perda de umidade e taxa de secagem de queijos prato, foram realizadas através da correlação linear pelo software Excel 10.0, sendo consideradas significativas quando $r>0,75$.

\section{Resultados e Discussões}

A Tabela I mostra os resultados para os 10 tratamentos realizados sobre o efeito do tempo de cozimento da massa de queijo, sobre a temperatura final do sistema após o cozimento, a umidade inicial $\left(1^{\circ} \mathrm{dia}\right.$ de maturação), a umidade após 25 dias de maturação, a perda total de umidade e a taxa de secagem do produto. 


\begin{tabular}{lcccccc}
\hline & $\begin{array}{c}\text { Tempo de } \\
\text { cozimento }(\mathbf{m i n})\end{array}$ & $\begin{array}{c}\text { Temperatura final } \\
\text { da massa }\left({ }^{\circ} \mathbf{C}\right)\end{array}$ & $\begin{array}{c}\text { Umidade } \\
\text { inicial (\%) }\end{array}$ & $\begin{array}{c}\text { Umidade } \\
\text { Final (\%) }\end{array}$ & $\begin{array}{c}\text { Perda de } \\
\text { umidade (\%) }\end{array}$ & $\begin{array}{c}\text { Taxa de } \\
\text { secagem (dia-1) }\end{array}$ \\
\hline Tratamento I & 18,5 & 41,3 & 43,10 & 40,00 & 2,99 & $3,18.10^{-3}$ \\
Tratamento 2 & 20,5 & 41,9 & 40,51 & 39,00 & 1,51 & $1,31.10^{-3}$ \\
Tratamento 3 & 19,0 & 41,7 & 41,95 & 40,00 & 1,94 & $1,99.10^{-3}$ \\
Tratamento 4 & 20,5 & 42,4 & 39,90 & 38,04 & 1,86 & $1,77.10^{-3}$ \\
Tratamento 5 & 17,5 & 40,3 & 44,32 & 41,03 & 3,29 & $2,61.10^{-3}$ \\
Tratamento 6 & 17,5 & 40,2 & 44,81 & 41,63 & 3,18 & $3,10.10^{-3}$ \\
Tratamento 7 & 18,0 & 40,8 & 42,91 & 40,00 & 2,91 & $3,21.10^{-3}$ \\
Tratamento 8 & 17,0 & 40,3 & 44,98 & 42,60 & 2,37 & $2,14.10^{-3}$ \\
Tratamento 9 & 22,0 & 42,9 & 38,97 & 37,14 & 1,83 & $2,14.10^{-3}$ \\
Tratamento 10 & 16,0 & 40,2 & 45,70 & 42,86 & 2,84 & $2,59.10^{-3}$ \\
\hline
\end{tabular}

A temperatura final da massa dos queijos variou entre $40,2^{\circ} \mathrm{C}$ (tratamento 10 ) e $42,9^{\circ} \mathrm{C}$ (tratamento 9), respectivamente implicando na variação do tempo de cozimento da massa entre 16 e 22 minutos. Esses parâmetros impactaram na umidade inicial do produto, que variou entre $38,97 \%$ e $45,70 \%$. A perda de umidade (diferença entre a umidade no início e no final da maturação) variou entre I,5 e 3\%, e a taxa de secagem entre $1,3 \mathrm{I} \cdot 10^{-3}$ e $3,18 \cdot 10^{-3} \mathrm{dia}^{-1}$. Um dos fatores que promove alteração na textura dos queijos é o teor de umidade final, que exerce grande influência sobre as modificações bioquímicas que ocorrem na maturação.

A proteólise é um processo que ocorre durante a maturação de diversos tipos de queijos, ocasionando alterações na textura, provenientes da quebra da rede de proteínas, aumentando o $\mathrm{pH}$ e conferindo maior ligação da água com grupos carboxil e amino formados (BARROS et al., 20I I). Antes de ocorrer a proteólise, a matriz caseínica é caracterizada por ser elástica. Durante a maturação, devido à ação conjunta das proteases e peptidases torna-se mais rígida. A compactação da microestrutura é decorrente da redução gradual da umidade, causada pela evaporação da água na superfície do queijo (BARROS et al., 20I I)

Durante o presente estudo as amostras foram armazenadas em câmara de maturação à temperatura de $5,5 \pm 0,5^{\circ} \mathrm{C}$ e umidade relativa de $81,9 \pm 0,3 \%$. A maturação em câmara fria com controle de umidade relativa do ar entre $70 \%$ e $90 \%$ e temperatura máxima de $12^{\circ} \mathrm{C}$, evita possíveis defeitos e perda excessiva de umidade (TOLENTINO, 20I3).

Os resultados mostram que a umidade dos queijos ao final de 25 dias de maturação se manteve entre 37 e 43\%, conforme a Tabela I, indicando que os tratamentos se enquadram com a legislação brasileira, que exige umidade do Queijo Prato (Lanche) após sua maturação de 36 a 45,9\% (BRASIL, I997).

Martins (2000) cita que as etapas de industrialização são de grande relevância para qualidade final do produto e lucratividade da indústria e ainda que a temperatura e cozimento da massa exercem grande influência no rendimento, pois esta temperatura controla a umidade final do queijo.

A pasteurização realizada como tratamento térmico no leite a ser utilizada para produção de queijos diminui a velocidade do processo de sinérese, devido às mudanças na estrutura da caseína. $A$ umidade do queijo é atribuída pela imobilização da água por parte das proteínas do leite, após a interação entre a caseína e as proteínas do soro provocada pela pasteurização. As micelas das caseínas, envolvidas pelas proteínas solúveis ficam impossibilitadas de interagir umas com as outras, reduzindo a expulsão do soro, o que leva à formação de um coágulo mais macio que retém mais umidade (JOHNSON, 1998).

Durante a coagulação, as micelas de caseína conservam sua estrutura e a coalhada retém a maior parte do cálcio e fosforo, promovendo o gel da coalhada bastante estável. A sinérese (saída do soro) é ocasionada quando se procede o corte, agitação e aquecimento da massa. O controle da sinérese pode ser feito pelo controle da temperatura do cozimento, intensidade de agitação e tamanho dos grãos, estes fatores têm influência na umidade final do produto (PAULA et al., 2009). Pode-se observar nos tratamentos 5, 6, 8 e 10 
(Tabela I), onde a sinérese foi menos intensa, devido ao menor tempo de cozimento da massa láctea, estes que por sua vez apresentam temperatura da massa láctea menor ao final da etapa de cozimento, comparando com os outros tratamentos e maior teor de umidade analisado no início do processo de maturação.

A Tabela 2 mostra a relação estatística entre os parâmetros analisados, sendo que a relação positiva mostra que o aumento de um parâmetro implica no aumento linear proporcional do parâmetro relacionado e a relação negativa mostra que o aumento de um parâmetro implica na diminuição linear proporcional do parâmetro relacionado. Neste estudo, os resultados indicam que o aumento do tempo de cozimento implica no aumento da temperatura final da massa do queijo $(r=+0,967)$. $O$ tempo de cozimento e a temperatura final da massa do queijo possuem relação negativa com a umidade inicial $(r=-0,984, r=-0,982$, respectivamente), umidade final $(r=-0,964, r=-0,947$, respectivamente) e perda de umidade total do produto ( $r=-$ $0,756, r=-0,802$, respectivamente). Ou seja, o aumento do tempo de cozimento e, consequentemente, da temperatura final da massa, implica em menores valores de umidade inicial e final, além de menor perda de umidade do produto durante a maturação. Não houve relação entre o tempo de cozimento ou a temperatura final da massa com a taxa de secagem.

Krolow e Ribeiro (2006) explicam que ao adicionar água quente sobre a massa, tem-se como finalidade lavar a massa, removendo parcialmente a lactose dos grãos devido a contração dos grãos e o efeito osmótico. O calor gerado pelo aquecimento da massa afeta a estrutura da matriz caseínica e leva à contração gradual da mesma, expulsando o soro e removendo parcialmente a lactose, diminuindo o teor de umidade da massa láctea. Assim ressalta-se que nos tratamentos 2, 4 e 9, conforme Tabela I, quanto maior for o tempo de cozimento, maior será a temperatura da massa ao fim do processo e menor o teor de umidade do queijo, nestes tratamentos o tempo de aquecimento foi maior, aumentando a contração do grão e facilitando a saída de umidade da massa.

Tabela 2 - Valores de $r$ calculados através de correlação de Pearson para a correlação linear dos parâmetros da avaliação do tempo de cozimento da massa de queijo prato (lanche) sobre a umidade do produto maturado

\begin{tabular}{lcccccc}
\hline & $\begin{array}{c}\text { Tempo de } \\
\text { cozimento }\end{array}$ & $\begin{array}{c}\text { Temperatura } \\
\text { final da massa }\end{array}$ & $\begin{array}{c}\text { Umidade } \\
\text { inicial }\end{array}$ & $\begin{array}{c}\text { Umidade } \\
\text { Final }\end{array}$ & $\begin{array}{c}\text { Perda de } \\
\text { umidade }\end{array}$ & $\begin{array}{c}\text { Taxa de } \\
\text { secagem }\end{array}$ \\
\hline Tempo de cozimento & - & $+0,967$ & $-0,984$ & $-0,964$ & $-0,756$ & $-0,556$ \\
Temperatura final da massa & - & $-0,982$ & $-0,947$ & $-0,802$ & $-0,574$ \\
Umidade inicial & - & - & $+0,976$ & $+0,781$ & $+0,567$ \\
Umidade final & & & - & $+0,623$ & $+0,398$ \\
Perda de umidade & & & & - & $+0,893$ \\
\hline
\end{tabular}

A umidade inicial do produto se mostrou estar relacionada positivamente com a umidade final $(r=+0,976)$, além de estar relacionado positivamente com a perda de umidade total $(r=+0,78 \mathrm{I})$. Neste sentido, quanto maior a umidade inicial da massa de queijo, maior é a perda de umidade na câmara de maturação e maior é a umidade final do produto (Tabela 2). Nos queijos com baixa umidade, o processo de maturação é mais lento, consequentemente menor perda de umidade (PAULA et al., 2009).

\section{Conclusão}

O tempo de cozimento da massa de Queijo Prato (Lanche) está relacionado com a umidade inicial e final do produto, além de se relacionar com a perda total de umidade. Esse parâmetro de processo não está relacionado com a taxa de secagem. Os resultados apontam que ao utilizar temperatura final da massa dos queijos entre $40,2^{\circ} \mathrm{C}$ e $42,9^{\circ} \mathrm{C}$, com variação do tempo de cozimento da massa entre 16 e 22 minutos, maior o tempo de cozimento e, consequentemente a sua temperatura ao final do cozimento, menores serão os valores de umidade inicial, umidade final e haverá menores perdas de umidade do queijo armazenado nas câmaras de maturação. Destacando assim, pequenas alterações no tempo de cozimento implicam em significativas mudanças na umidade do queijo maturado. Para man- 
ter os padrões dentro dos parâmetros definidos pela legislação é importante o controle do tempo de cozimento da massa entre 17 e 22 minutos.

É importante, também, desenvolver mais pesquisas aplicando maior número de amostras com intuito de avaliar outros aspectos no processo de industrialização, como a influência da temperatura e umidade utilizada na câmara fria durante o período de maturação do Queijo Prato (Lanche) sobre a umidade final do produto.

\section{Referências}

BARROS, J. J. C. et al. Queijo Parmesão: caracterização físico-química, microbiológica e microestrutura. Ciência e Tecnologia de Alimentos, v. 3I, n. I, p. 285-294, 201 I.

BRASIL. Portaria $n^{\circ}$ 358, de 04 de setembro de 1997. Aprova o regulamento técnico para fixação de identidade e qualidade de Queijo Prato. Diário Oficial [da] República Federativa do Brasil, Brasília. 1997. Disponível em: http:// www.crmvgo.org.br/legislacao/leite/POR00000358.pdf. Acesso em: 14 fev. 2016.

BRASIL. Portaria $\mathrm{n}^{\circ}$ 146, de 07 de março de 1996. Aprova regulamentos técnicos de identidade e qualidade dos produtos lácteos. Diário Oficial [da] República Federativa do Brasil, Brasília, DF, II mar. 1996. Disponível em: http:// www.crmvgo.org.br/legislacao/leite/POR00000352.pdf. Acesso em: I4 fev. 2016.

BRASIL. Instrução Normativa $\mathrm{n}^{\circ}$. 68, de 12 dezembro de 2006. Métodos analíticos físico-químicos para o controle de leite e produtos lácteos. Diário Oficial [da] República Federativa do Brasil, Brasília, DF, 12 dez. 2006. Disponível em: http://extranet.agricultura.gov.br/sislegis-consulta/servlet/VisualizarAnexo?id=12398. Acesso em: 10 fev. 2016.

CHALITA, M. A. N. et al. Algumas considerações sobre a fragilidade das concepções de qualidade no mercado de queijos no brasil. Informações Econômicas, v. 39, n. 6, p. 77-88, 2009.

CHAVES, K. D. S. Avaliação da maturação e perfil sensorial de queijos Prato probióticos tipo Lanche adicionado de Lactobacillus acidophilus La-5 e Bifidobacterium Bb-12. p. 95. Tese (Doutorado em Tecnologia de Alimentos) - Universidade Estadual de Campinas - Campinas, 2014.

DALLA ROSA, T. et al. Microbiological and physicochemical characteristics and aminopeptidase activities during ripening of serrano cheese. International Journal of Dairy Technology, v. 6I, n. I, p. 70-79, 2008.

PAULA, J. C. J. de; CARVALHO, A. F; FURTADO, M. M. Princípios básicos de fabricação de queijo: do histórico à salga. Revista do Instituto de Laticínios “Cândido Tostes", v. 64, p. 19-25, 2009.

JOHNSON, M. E. Cheese Chemistry - Part II. In: WONG N. P.; JENNESS R.; KEENEY M. Fundamentals of dairy chemistry. New York: Third Edition. Van Nostrand Reinhold, 1998. p. 634-654.

KROLOW, A. C. R.; RIBEIRO, M. E. R. Obtenção de leite com qualidade e elaboração de derivados. Documentos I54 Pelotas: Embrapa Clima Temperado, p. 66, 2006.

MARTINS, E. Manual técnico na arte e princípios da fabricação de queijos. Paraná: Gráfica e editora Campana Ltda., 2000. p. I0I. Disponível em: http://coalhopar.com.br/novidade/manual-tecnico-na-arte-e-principios-da-fabricacao-de-queijos. Acesso em: 20 de fev. 2016.

NARIMATSU, A. et al. Avaliação da proteólise e do derretimento do Queijo Prato obtido por ultrafiltração. Ciência Tecnologia de Alimentos, v. 23, p. 177-182, 2003.

ORDÓÑEZ, J. A. P. (Org.). Tecnologia de Alimentos. Porto Alegre: Artmed, 2005. v. 2, p. 85-103, Cap. 5.

PERRY, K. S. P. Queijos: aspectos químicos, bioquímicos e microbiológicos. Química Nova, v. 27, n. 2, p. 293-300, 2004.

SILVA, F. T. Queijo Prato. Brasília: Embrapa Informação Tecnológica (Agroindústria Familiar), 2005. p. 54. Disponível em: https://ainfo.cnptia.embrapa.br/digital/bitstream/item/l 1887/2/00076230.pdf. Acesso em: 06 de jan. 2016.

TOLENTINO, M. C. Desenvolvimento e caracterização de queijo de massa semidura recoberto com alecrim (Rosmarinus officinalis L.). Curitiba, PR. 2013, p. 120. Tese (doutorado) - Universidade Federal do Paraná - Programa de Pós-Graduação em Engenharia de Alimentos, 2013. 